\title{
Comparison of the Risk of Psychological and Cognitive Disorders Between Persistent and Nonpersistent Statin Users
}

\author{
Steven M. Lilly, MD ${ }^{\mathrm{a}}$, Eric M. Mortensen, MD, MSc ${ }^{\mathrm{a}}$, Christopher R. Frei, PharmD, MSc ${ }^{\mathrm{b}, \mathrm{c}}$, \\ Mary Jo Pugh, $\mathrm{PhD}^{\mathrm{d}}$, and Ishak A. Mansi, MD ${ }^{\mathrm{a}, *}$
}

\begin{abstract}
Despite their cardiovascular benefits, statin use has been associated with a wide array of actual or perceived psychological and cognitive adverse events. The objective of this study was to compare baseline characteristics and the risk of developing psychological and cognitive disorders between persistent and nonpersistent statin users. We performed a retrospective cohort study (October 1, 2003, to March 1, 2010) of 13,626 statin users in a regional US military health-care system. The persistence of statin use was defined by cumulative pharmacy fill data. Outcomes were the occurrence of psychological diseases during follow-up using prespecified groups based on International Classification of Diseases, Ninth Revision, codes: (1) schizophrenia and psychosis, (2) major depression and bipolar disorders, (3) all psychological diseases, and (4) dementia and cognitive disorders. Statin users who were nonpersistent at 2 years were younger, less likely to be men, and had fewer co-morbidities than persistent users. They were also more likely to be diagnosed with schizophrenia or psychosis (odds ratio [OR] 1.58, 95\% confidence interval [CI] 1.20 to 2.10) and cognitive disorders (OR 1.56, 95\% CI 1.19 to 2.03 ) during follow-up compared with persistent users. There was not an association between nonpersistence at 2 years and the development of depression and bipolar disorders (OR $0.99,95 \%$ CI 0.85 to 1.15) or combined psychological diseases (OR 0.97, 95\% CI 0.86 to 1.09). Cumulative persistence with statin therapy as a continuous measure was associated with less risk of all outcomes. In conclusion, persistent statin users did not demonstrate an increase in the diagnosis of psychological disorders compared with nonpersistent users. Nonpersistent statin use was associated with a greater likelihood of being diagnosed with psychotic or cognitive disorders. Published by Elsevier Inc. (Am J Cardiol 2014;114:1035-1039)
\end{abstract}

Several conflicting reports have examined the association of statins (hydroxymethylglutaryl coenzyme-A reductase inhibitors) and the risk of psychological and cognitive disorders. $^{1-4}$ Beyond the issue of whether statin use is associated with psychological side effects, the relation

${ }^{\mathrm{a}}$ Department of Internal Medicine, Veterans Affairs North Texas Health Care System and University of Texas Southwestern Medical Center, Dallas, Texas; ${ }^{b}$ College of Pharmacy, The University of Texas at Austin, Austin, Texas; 'Pharmacotherapy Education and Research Center, School of Medicine, University of Texas Health Science Center, San Antonio, Texas; and ${ }^{\mathrm{d}}$ Department of Epidemiology and Biostatistics, Veterans Affairs South Texas Health Care System and University of Texas Health Science Center, San Antonio, Texas. Manuscript received April 23, 2014; revised manuscript received and accepted July 2, 2014.

No funding was provided for the conduct of this study or the preparation of this report.

This report is the result of work supported with resources and the use of facilities at the Veterans Affairs North Texas Health Care System. The views expressed herein are those of the authors and do not reflect the official policy or position of the Department of the Army, Department of Defense, or the Department of Veterans Affairs. Four of the authors are employees of the US government. This work was prepared as part of their official duties and, as such, there is no copyright to be transferred.

See page 1038 for disclosure information.

*Corresponding author: Tel: (214) 857-1588; fax: (214) 857-1575.

E-mail address: Ishak.mansi@va.gov (I.A. Mansi). between persistence with statin therapy and the development of these disorders is unclear. Understanding such a relation, if one exists, is important for both providers and patients to improve guideline-based adherence to statin therapy. To our knowledge, no cohort or randomized controlled study has compared the prevalence of psychological disorders in statin users based on patient persistence with therapy. The objective of this study was to compare the baseline characteristics and risk of developing psychological and cognitive disorders between statin users who are persistent and nonpersistent with statin therapy.

\section{Methods}

This study was approved by the Institutional Review Board at the Brooke Army Medical Center. All inpatient and outpatient medical encounters, diagnoses, and medication fill histories were retrieved using the Military Health System Management Analysis and Reporting Tool (M2), ${ }^{5}$ as previously published. ${ }^{6}$ The study was divided into 2 periods: baseline period (October 1, 2003, to September 30, 2005) and follow-up period (October 1, 2005, to March 5, 2010). We included all patients aged 30 to 85 years who were enrolled in the San Antonio Military Area as Tricare Prime or Plus, who had at least 1 encounter during the baseline and follow-up periods and received a statin during the fiscal year 2005 for $\geq 90$ days. Using International Classification of 
Table 1

Comparison of baseline characteristics for patients who were persistent and nonpersistent with statin therapy at 2 years

\begin{tabular}{|c|c|c|c|}
\hline Variable & $\begin{array}{c}\text { Persistent } \\
(\mathrm{N}=12006)\end{array}$ & $\begin{array}{l}\text { Non-Persistent } \\
(\mathrm{N}=1620)\end{array}$ & $\mathrm{p}$-Value \\
\hline Mean age (years) $\pm \mathrm{SD}$ & $61.3 \pm 11.9$ & $53.6 \pm 12.4$ & $<0.0001$ \\
\hline Women & $4964(41 \%)$ & $715(44 \%)$ & 0.03 \\
\hline \multicolumn{4}{|l|}{ Comorbidities } \\
\hline $\begin{array}{l}\text { Acute myocardial } \\
\text { infarction }\end{array}$ & $745(6.2 \%)$ & $52(3.2 \%)$ & $<0.0001$ \\
\hline Congestive heart failure & $698(5.8 \%)$ & $48(3.0 \%)$ & $<0.0001$ \\
\hline $\begin{array}{l}\text { Peripheral vascular } \\
\text { disease }\end{array}$ & $809(6.7 \%)$ & $50(3.1 \%)$ & $<0.0001$ \\
\hline Cerebrovascular disease & $499(4.2 \%)$ & $52(3.2 \%)$ & 0.07 \\
\hline Dementia & $51(0.4 \%)$ & $7(0.4 \%)$ & 0.99 \\
\hline $\begin{array}{l}\text { Chronic obstructive } \\
\text { pulmonary disease }\end{array}$ & $1859(16 \%)$ & $206(13 \%)$ & 0.003 \\
\hline Rheumatologic disease & $254(2.1 \%)$ & $36(2.2 \%)$ & 0.8 \\
\hline Peptic ulcer disease & $202(1.7 \%)$ & $18(1.1 \%)$ & 0.1 \\
\hline Mild liver disease & $43(0.4 \%)$ & $5(0.3 \%)$ & 0.5 \\
\hline Diabetes mellitus & $4035(34 \%)$ & $351(22 \%)$ & $<0.0001$ \\
\hline $\begin{array}{l}\text { Diabetes mellitus with } \\
\text { complications }\end{array}$ & $1548(13 \%)$ & $115(7 \%)$ & $<0.0001$ \\
\hline Hemiplegia/paraplegia & $46(0.4 \%)$ & $3(0.2 \%)$ & 0.3 \\
\hline Renal disease & $432(3.6 \%)$ & $39(2.4 \%)$ & 0.02 \\
\hline Malignancy & $916(7.6 \%)$ & $94(5.8 \%)$ & $<0.0001$ \\
\hline $\begin{array}{l}\text { Liver disease (moderate/ } \\
\text { severe) }\end{array}$ & $7(0.1 \%)$ & $1(0.1 \%)$ & 0.99 \\
\hline Metastatic neoplasm & $43(0.4 \%)$ & $5(0.3 \%)$ & 0.99 \\
\hline HIV & $9(0.1 \%)$ & $4(0.2 \%)$ & 0.06 \\
\hline $\begin{array}{l}\text { Charlson comorbidity score: } \\
\text { mean } \pm \mathrm{SD}\end{array}$ & $1.28 \pm 1.65$ & $0.85 \pm 1.39$ & $<0.0001$ \\
\hline $\begin{array}{l}\text { Psychological disorders at } \\
\text { baseline }\end{array}$ & $1191(16 \%)$ & $257(16 \%)$ & 0.99 \\
\hline Illicit drugs use & $17(0.1 \%)$ & $3(0.2 \%)$ & 0.35 \\
\hline Alcohol abuse/dependence & $109(0.9 \%)$ & $24(1.5 \%)$ & 0.04 \\
\hline Smoking & $1043(8.7 \%)$ & $183(11 \%)$ & 0.001 \\
\hline Obesity* & $2076(17 \%)$ & $320(20 \%)$ & 0.02 \\
\hline Vision defects/blindness & $5521(46 \%)$ & $726(45 \%)$ & 0.4 \\
\hline $\begin{array}{l}\text { Mean HDL-C (mg/dL): } \\
\quad \text { mean } \pm \mathrm{SD}\end{array}$ & $52.4 \pm 14.3$ & $53.1 \pm 15.8$ & 0.2 \\
\hline $\begin{array}{l}\text { Mean LDL-C }(\mathrm{mg} / \mathrm{dL}) \text { : } \\
\quad \text { mean } \pm \mathrm{SD}\end{array}$ & $102 \pm 31.1$ & $133.2 \pm 43.4$ & $<0.0001$ \\
\hline $\begin{array}{l}\text { Number of outpatient } \\
\text { visits } \pm \mathrm{SD}\end{array}$ & $42 \pm 44.9$ & $35 \pm 42.6$ & $<0.0001$ \\
\hline $\begin{array}{l}\text { Number of inpatient } \\
\text { admissions } \pm \mathrm{SD}\end{array}$ & $0.45 \pm 1.04$ & $0.37 \pm 0.86$ & 0.002 \\
\hline \multicolumn{4}{|l|}{ Medications } \\
\hline Beta-blocker & $3572(30 \%)$ & $336(21 \%)$ & $<0.0001$ \\
\hline Diuretic & $4592(38 \%)$ & $525(32 \%)$ & $<0.0001$ \\
\hline Calcium channel blocker & $3205(27 \%)$ & $309(20 \%)$ & $<0.0001$ \\
\hline $\begin{array}{l}\text { Non-statin lipid lowering } \\
\text { drugs }\end{array}$ & $2033(17 \%)$ & $288(18 \%)$ & 0.4 \\
\hline ACE/ARB & $7301(61 \%)$ & $681(42 \%)$ & $<0.0001$ \\
\hline Oral hypoglycemic & $2592(22 \%)$ & $228(14 \%)$ & $<0.0001$ \\
\hline Cytochrome P450 drug & $1313(11 \%)$ & $151(9 \%)$ & 0.05 \\
\hline Aspirin & $6631(55 \%)$ & $643(40 \%)$ & $<0.0001$ \\
\hline NSAIDs & $6595(55 \%)$ & $973(60 \%)$ & $<0.0001$ \\
\hline SSRI & $2213(18 \%)$ & $300(19 \%)$ & 0.95 \\
\hline Systemic corticosteroid & $446(3.7 \%)$ & $86(5.3 \%)$ & 0.002 \\
\hline Antipsychotic & $157(1.3 \%)$ & $23(1.4 \%)$ & 0.7 \\
\hline Sedatives & $2593(21 \%)$ & $323(20 \%)$ & 0.3 \\
\hline Tricyclic anti-depressants & $30(0.2 \%)$ & $5(0.3 \%)$ & 0.6 \\
\hline
\end{tabular}

Table 1

(continued)

\begin{tabular}{lccc}
\hline Variable & $\begin{array}{c}\text { Persistent } \\
(\mathrm{N}=12006)\end{array}$ & $\begin{array}{c}\text { Non-Persistent } \\
(\mathrm{N}=1620)\end{array}$ & p-Value \\
\hline $\begin{array}{c}\text { Statin utilization } \\
\text { Received intensive statin } \\
\text { therapy }^{\dagger}\end{array}$ & $4296(36 \%)$ & $291(18 \%)$ & $<0.0001$ \\
\hline
\end{tabular}

Cytochrome p 450 drugs are medications that inhibit the Cytochrome p450 system as identified in a recent Food and Drug Administration warning. ${ }^{11}$

$\mathrm{ACE} / \mathrm{ARB}=$ angiotensin receptor blocker/angiotensin-converting enzyme inhibitor; NSAID $=$ nonsteroidal anti-inflammatory drug; SSRI $=$ selective serotonin reuptake inhibitor.

* Obesity was identified using ICD-9-CM codes 2780, 27800, 27801, 27802, 27803, 2781, 2788, and 7831.

${ }^{\dagger}$ Intensive statin therapy as identified in recent guidelines. ${ }^{14}$

Diseases, Ninth Revision, Clinical Modification [ICD-9-CM] codes, we excluded trauma and burn patients (as defined by the Agency for Health Research Quality Clinical Classifications Software [AHRQ-CCS] category 240) ${ }^{7}$ and previous publications. $^{8}$ AHRQ-CCS is a diagnosis and procedure categorization scheme that can be used in analyzing data on diagnoses and procedures using ICD-9-CM codes. AHRQCCS collapses multitude of diagnoses and procedures into a smaller number of clinical categories of diseases.

We calculated the cumulative days of statin use as the sum of statin supply days that were dispensed from the pharmacy. Our data captured all medication supplies regardless of pharmacy site or affiliation. Because there is no standard definition for persistence with statin therapy, we used the following definitions: (1) 1-year nonpersistent use: defined as patients who used statins for a cumulative period of 90 to 364 days, whereas persistent users had a cumulative statin use of $\geq 365$ days; (2) 2-year nonpersistent use: defined as patients who used statins for a cumulative period of 90 to 729 days, whereas persistent users at 2 years had a cumulative statin use of $\geq 730$ days; (3) 4-year nonpersistent use: defined as patients who used statins for a cumulative period of 90 to 1,459 days, whereas persistent users at 4 years had a cumulative statin use of $\geq 1,460$ days; and (4) cumulative years of persistence with statin therapy as a continuous measure for persistence.

The occurrence of an ICD-9-CM code during the followup period, as defined later, in either the inpatient or outpatient setting constituted an outcome event. We used prespecified outcome diagnosis groups to define psychological diseases as described in a previous publication. ${ }^{6}$ Briefly, these outcomes were (1) schizophrenia and other psychosis: including codes for schizophrenia, schizoaffective disorders, and other psychosis as identified in the Veterans Aging Cohort Study'; (2) depression and bipolar disorder: including codes for major depression, bipolar disorders, and post-traumatic stress disorder as identified in Veterans Aging Cohort Study; (3) all psychological diseases and disorders: consisting of all ICD-9 codes for psychological diseases as identified by AHRQ-CCS, ${ }^{7}$ except for categories of childhood or developmental psychiatric 
Table 2

Number of persistent versus nonpersistent statin users at predefined intervals of cumulative statin use

\begin{tabular}{lccc}
\hline $\begin{array}{l}\text { Interval of Cumulative } \\
\text { Statin Use }\end{array}$ & Total & $\begin{array}{c}\text { Persistent Users } \\
\mathrm{N}(\%)\end{array}$ & $\begin{array}{c}\text { Non-Persistent Users } \\
\mathrm{N}(\%)\end{array}$ \\
\hline 1 Year & 13626 & $12883(94.5 \%)$ & $743(5.5 \%)$ \\
2 Years & 13626 & $12006(88 \%)$ & $1620(12 \%)$ \\
4 Years & 13626 & $9322(68 \%)$ & $4304(32 \%)$ \\
\hline
\end{tabular}

Table 3

Risks of developing psychological and cognitive disorders comparing patients who are nonpersistent to those who are persistent with statin therapy

\begin{tabular}{lc}
\hline Diagnostic Groups & $\begin{array}{c}\text { AOR }(95 \% \text { CI })^{*} \\
\text { Entire Study Period) }\end{array}$ \\
\hline Psych 1 (schizophrenia/other psychosis) & \\
1-Year non-persistent $(\mathrm{n}=743)$ & $1.66(1.1-2.5)$ \\
2-Year non-persistent $(\mathrm{n}=1620)$ & $1.58(1.2-2.1)$ \\
4-Year non-persistent $(\mathrm{n}=4304)$ & $1.53(1.28-1.83)$ \\
Cumulative persistence & $0.87(0.83-0.91)$ \\
Psych 2 (depression/bipolar disorder) & \\
1-Year non-persistent & $0.89(0.69-1.08)$ \\
2-Year non-persistent & $0.99(0.85-1.15)$ \\
4-Year non-persistent & $1.25(1.12-1.39)$ \\
Cumulative persistence & $0.95(0.92-0.97)$ \\
Psych 3 (all psychological diseases) & \\
1-Year non-persistent & $0.85(0.72-1.0)$ \\
2-Year non-persistent & $0.97(0.86-1.09)$ \\
4-Year non-persistent & $1.12(1.03-1.22)$ \\
Cumulative persistence & $0.98(0.96-0.996)$ \\
Psych 4 (cognitive disorders) & \\
1-Year non-persistent & $1.59(1.07-2.37)$ \\
2-Year non-persistent & $1.56(1.19-2.03)$ \\
4-Year non-persistent & $1.59(1.34-1.88)$ \\
Cumulative persistence & $0.87(0.83-0.91)$ \\
\hline
\end{tabular}

$\mathrm{AOR}=$ adjusted odds ratio; $\mathrm{CI}=$ confidence interval.

* Adjusted for patient's age, gender, number of all outpatient medical encounters, number of all inpatient admissions, Charlson co-morbidity score, psychological diseases at baseline, alcohol dependence/abuse, tobacco use, obesity, vision defects/blindness, and use of the following medication classes: $\beta$ blockers, diuretics, calcium channel blockers, nonstatin lipid-lowering agents, renin-angiotensin system inhibitors, oral hypoglycemic agents, steroids, cytochrome p450, aspirin, nonsteroidal antiinflammatory drugs, selective serotonin reuptake inhibitors, antipsychotics, and sedatives.

${ }^{\dagger}$ Cumulative persistence denotes cumulative years of persistence with statin therapy as an exposure variable in multivariate logistic regression analysis.

disorders (categories 654 and 655); this group included adjustment disorders (category 650), anxiety disorders (category 651), attention-deficit and disruptive behavior disorders (category 652), impulse control disorders (category 656), mood disorders (category 657), personality disorders (category 658), schizophrenia and other psychotic disorders (category 659), and miscellaneous disorders (category 670); and (4) cognitive disorders: including codes for delirium, dementia, and amnestic and other cognitive disorders as identified by AHRQ-CCS (category 653).
Patients' baseline characteristics are described using the Charlson comorbidity index described by Deyo et al ${ }^{10}$ social habits, presence of psychological diseases at baseline, and other comorbid conditions and medication use as in shown in Table 1. ${ }^{11}$ Baseline characteristics were compared using chisquare and Student $t$ tests as appropriate. Comparisons were considered statistically significant if the calculated 2-tailed $\mathrm{p}$ value was $\leq 0.05$. We used separate multivariate logistic regression models to examine the risk of each outcome in which each psychological/cognitive outcome was a dependent variable, and persistence measure was an exposure variable (each of 1-year nonpersistent, 2-year nonpersistent, 4-year nonpersistent, and cumulative years of persistence with statin therapy in a separate model), adjusting for potential confounders. Statistical analyses were performed using SPSS statistical software, version 19 (IBM Corp, Armonk, New York).

\section{Results}

A total of 60,891 patients were identified, and the following patients were excluded: 2,124 trauma patients, 2,042 patients who did not receive any medication during the baseline period, 32,623 patients who did not use a statin, and 10,476 patients who received their first dose of statins after the baseline period (September 30, 2005). The remaining patients included 13,626 statin users. The mean (SD) cumulative duration of statin use was 1,695 days (662), with a median (interquartile range) of 1,860 days $(1,260$ to 2,220$)$. During the study period, $73.5 \%$ of statins prescriptions were simvastatin, $17.4 \%$ atorvastatin, $7 \%$ pravastatin, $1.7 \%$ rosuvastatin, and $0.24 \%$ fluvastatin or lovastatin.

Table 1 compares baseline characteristics for statin users who were persistent and nonpersistent at 2 years. Persistent statin users were older, more likely to be men, had increased co-morbidities including cardiovascular diagnoses, and received more intensive statin therapy. Importantly, the prevalence of psychological disorders at the beginning of the study was the same in both groups. Table 2 lists the number of patients who satisfied the criteria of persistent and nonpersistent statin use at each predefined interval of cumulative statin use.

The adjusted odds ratios comparing the prevalence of psychological diagnoses between persistent and nonpersistent statin users are reported in Table 3. There were higher adjusted odds ratios for schizophrenia and psychosis and cognitive disorders in nonpersistent patients. There was a slight increase in the risk of being diagnosed with depression and bipolar disorders and all psychological diagnoses in the 4-year nonpersistent but not in the 2-year nonpersistent statin users compared with persistent users. Cumulative years of persistence with statin therapy as a continuous measure was associated with less risk of all outcomes.

\section{Discussion}

This study described the characteristics of persistent and nonpersistent statin users and examined their risk of being diagnosed with psychological and cognitive diseases. There is a significant paucity of data regarding the risk of psychological side effects as it relates to statin persistence. This 
topic is important because persistence may contribute to differences in statin efficacy commonly noted between clinical trials and real-world practice. ${ }^{12}$

Medication persistence refers to patient's continuation of a prescribed drug therapy throughout the overall duration of drug therapy, whereas adherence refers to the degree to which a patient's medication-taking behavior coincides with agreed medical advice. ${ }^{13}$ Adherence can also be viewed as a component of persistence. This study showed that persistent statin users were older, included a greater proportion of men, used more health-care services, and had more comorbidities than nonpersistent users. These results have clinical relevance because the 2013 cholesterol treatment guidelines would extend treatment to a population with fewer co-morbid conditions. ${ }^{14}$ Therefore, ensuring persistence with therapy, not only starting it, may require additional effort. Several studies have noted similar findings. ${ }^{15,16}$ A large meta-analysis showed that women and those with lower income levels were less likely to be persistent users. ${ }^{17}$ Overall, statin persistence in our population was greater than that reported in other populations. ${ }^{17,18}$

With regard to risk of developing psychological and cognitive disorders in relation to statin persistence, our outcome data showed that nonpersistent statin users had a greater risk of being diagnosed with schizophrenia/psychosis (psych 1) and cognitive disorders (psych 4) compared with persistent users. The interpretation of these results can be challenging. It may be hypothesized that persistent statin use was protective against developing psych 1 and 4 diagnoses. Although a recent meta-analysis noted that statin use compared with nonuse was associated with less risk of cognitive dysfunction, ${ }^{19}$ no studies have examined such risks between nonpersistent and persistent statin users. It is more plausible, however, to surmise that patients who were prone to develop psychotic or cognitive disorders may have exhibited nonpersistence more frequently. For example, discontinuing statins in these patients may have been prompted by providers to facilitate care if the indications for statin use were less compelling in the setting of psychological illness. The predilection to these conditions likely contributed to inconsistent medication use. The patients themselves may have discontinued statins for such reasons as having greater innate patterns of nonadherence or experiencing actual or perceived adverse events.

This study has several strengths. First, we are unaware of other observational studies investigating the relation between statin persistence and psychological adverse events. Second, this study is not based on surveys or questionnaires but rather ICD-9 codes of psychological disease as placed in the patient record. This helps avoid response bias and inaccuracy associated with surveys. ${ }^{20}$ There are also several limitations to our study. Using diagnostic codes from an administrative database does not conclusively prove that these diagnoses are correct, although 2 studies have shown that administrative data have an accuracy of $86.8 \%$, specificity of $97.0 \%$ to $99.5 \%$ but variable sensitivity compared with clinical data in identifying mental health conditions. $^{21,22}$ The risk of developing psychological disorders in this military population may not be reflective of the general population. Additionally, the definition of statin persistence has significantly varied among different studies. ${ }^{23}$ Because this study is database research, we could not account for actual medication intake; rather we used pharmacy fills as a surrogate for persistence. We also could not determine if the outcome of interest was a class effect because patients used different statins at different doses throughout the study period. Studies have suggested that lipophilic versus hydrophilic statins may differ in their clinical action and side effects. $^{20}$ Although this study did not show that persistence with statin use was associated with increased risks of psychological or cognitive diseases, its observational nature precludes a cause-effect relation. These results may be considered, however, in examining the risk-to-benefit ratio of statin use in individual patients.

\section{Disclosures}

Dr. Frei was supported by the US National Institutes of Health in the form of an NIH/KL2 career development award (RR025766) during this work. In addition, he has received research grants and/or served as a scientific consultant/advisor for AstraZeneca, Bristol-Myers Squibb, Elan, Forest Laboratories, Ortho-McNeil Janssen, and Pfizer. The other authors have no conflicts of interest to disclose.

1. Morales K, Wittink M, Datto C, DiFilippo S, Cary M, TenHave T, Katz IR. Simvastatin causes changes in affective processes in elderly volunteers. J Am Geriatr Soc 2006;54:70-76.

2. Golomb BA, Kane T, Dimsdale JE. Severe irritability associated with statin cholesterol-lowering drugs. QJM 2004;97:229-235.

3. Stewart RA, Sharples KJ, North FM, Menkes DB, Baker J, Simes J. Long-term assessment of psychological well-being in a randomized placebo-controlled trial of cholesterol reduction with pravastatin. The LIPID Study Investigators. Arch Intern Med 2000;160: 3144-3152.

4. Young-Xu Y, Chan KA, Liao JK, Ravid S, Blatt CM. Long-term statin use and psychological well-being. J Am Coll Cardiol 2003;42: 690-697.

5. Kugler J. Military Health System Patient Centered Medical Home Guide, Office of the Chief Medical Officer. Tricare, Department of Defense, 2011:20.

6. Mansi I, Frei CR, Pugh MJ, Mortensen EM. Psychologic disorders and statin use: a propensity score-matched analysis. Pharmacotherapy 2013;33:615-626.

7. Elixhauser A, Steiner C, Palmer L. Clinical Classifications Software (CCS) for ICD-9-CM Databases and Related Tools from the Healthcare Cost and Utilization Project (HCUP). U.S. Agency for Healthcare Research and Quality, 2012; Appendix A.

8. Selim AJ, Fincke G, Ren XS, Lee A, Rogers WH, Miller DR, Skinner KM, Linzer M, Kazis LE. Comorbidity assessments based on patient report: results from the Veterans Health Study. J Ambul Care Manage 2004:27:281-295.

9. Skanderson M. Description of ICD-9 Comorbidity Codes Used by VACS (Veterans Aging Cohort Study); West Haven, CT 2006: $1-29$.

10. Deyo RA, Cherkin DC, Ciol MA. Adapting a clinical comorbidity index for use with ICD-9-CM administrative databases. J Clin Epidemiol 1992;45:613-619.

11. FDA Drug Safety Communication: New Restrictions, Contraindications, and Dose Limitations for Zocor (Simvastatin) to Reduce the Risk of Muscle Injury. U.S. Food and Drug Administration; U.S. Department of Health and Human Services, 2011.

12. Davidson MH. Differences between clinical trial efficacy and realworld effectiveness. Am J Manag Care 2006;12:S405-S411.

13. Cramer JA, Roy A, Burrell A, Fairchild CJ, Fuldeore MJ, Ollendorf DA, Wong PK. Medication compliance and persistence: terminology and definitions. Value Health 2008;11:44-47.

14. Stone NJ, Robinson J, Lichtenstein AH, Merz CN, Blum CB, Eckel RH, Goldberg AC, Gordon D, Levy D, Lloyd-Jones DM, McBride P, Schwartz JS, Shero ST, Smith SC Jr, Watson K, Wilson PW. 2013 
ACC/AHA Guideline on the Treatment of Blood Cholesterol to Reduce Atherosclerotic Cardiovascular Risk in Adults: a report of the American College of Cardiology/American Heart Association Task Force on Practice Guidelines. Circulation 2013. http://dx.doi.org/10.1161/01.cir. 0000437738.63853.7a; E-pub ahead of print.

15. Latry P, Molimard M, Dedieu B, Couffinhal T, Begaud B, MartinLatry K. Adherence with statins in a real-life setting is better when associated cardiovascular risk factors increase: a cohort study. $B M C$ Cardiovasc Disord 2011;11:46.

16. Cheetham TC, Niu F, Green K, Scott RD, Derose SF, Vansomphone SS, Shin J, Tunceli K, Reynolds K. Primary nonadherence to statin medications in a managed care organization. J Manag Care Pharm 2013;19:367-373.

17. Mann DM, Woodward M, Muntner P, Falzon L, Kronish I. Predictors of nonadherence to statins: a systematic review and meta-analysis. Ann Pharmacother 2010;44:1410-1421.
18. Kiss Z, Nagy L, Reiber I, Paragh G, Molnar MP, Rokszin G, AbonyiToth Z, Mark L. Persistence with statin therapy in Hungary. Arch Med Sci 2013;9:409-417.

19. Steenland K, Zhao L, Goldstein FC, Levey AI. Statins and cognitive decline in older adults with normal cognition or mild cognitive impairment. J Am Geriatr Soc 2013;61:1449-1455.

20. Mansi I, Mortensen E. The controversy of a wider statin utilization: why? Expert Opin Drug Saf 2013;12:327-337.

21. Steele LS, Glazier RH, Lin E, Evans M. Using administrative data to measure ambulatory mental health service provision in primary care. Med Care 2004;42:960-965.

22. Lurie N, Popkin M, Dysken M, Moscovice I, Finch M. Accuracy of diagnoses of schizophrenia in Medicaid claims. Hosp Community Psychiatry 1992;43:69-71.

23. Mauskop A, Borden WB. Predictors of statin adherence. Curr Cardiol Rep 2011;13:553-558. 